\title{
Prognostic and diagnostic impact of fibrinogen, neutrophil-to- Iymphocyte ratio, and platelet-to-lymphocyte ratio on thymic epithelial tumors outcome
}

\author{
Stefan Janik ${ }^{1,2}$, Thomas Raunegger ${ }^{1,2}$, Philipp Hacker ${ }^{1,2}$, Bahil Ghanim ${ }^{1}$, Elisa \\ Einwallner ${ }^{3}$, Leonhard Müllauer ${ }^{4}$, Ana-Iris Schiefer ${ }^{4}$, Julia Moser ${ }^{5}$, Walter Klepetko ${ }^{1}$, \\ Hendrik Jan Ankersmit ${ }^{1,2,6}$ and Bernhard Moser ${ }^{1}$ \\ ${ }^{1}$ Department of Thoracic Surgery, Division of Surgery, Medical University Vienna, Vienna, Austria \\ ${ }^{2}$ Christian Doppler Laboratory for Diagnosis and Regeneration of Cardiac and Thoracic Diseases, Medical University Vienna, \\ Vienna, Austria \\ ${ }^{3}$ Department of Laboratory Medicine, Medical University Vienna, Vienna, Austria \\ ${ }^{4}$ Clinical Institute of Pathology, Medical University Vienna, Vienna, Austria \\ ${ }^{5}$ Departments of Dermatology and Venereology and Karl Landsteiner Institute of Dermatological Research, Karl Landsteiner \\ University of Health Sciences, St. Pölten, Austria \\ ${ }^{6}$ Head FFG Project "APOSEC", FOLAB Surgery, Medical University Vienna, Vienna, Austria \\ Correspondence to: Bernhard Moser, email: bernhard.moser@meduniwien.ac.at \\ Keywords: thymic epithelial tumors; thymoma; thymic carcinoma; fibrinogen; NLR \\ Received: September 24, $2017 \quad$ Accepted: March 22, $2018 \quad$ Published: April 24, 2018 \\ Copyright: Janik et al. This is an open-access article distributed under the terms of the Creative Commons Attribution License 3.0 \\ (CC BY 3.0), which permits unrestricted use, distribution, and reproduction in any medium, provided the original author and source \\ are credited.
}

\section{ABSTRACT}

Background: Peripheral blood-derived inflammation-based markers, such as Neutrophil-to-Lymphocyte Ratio (NLR), Platelet-to-Lymphocyte Ratio (PLR), and Fibrinogen have been identified as prognostic markers in various solid malignancies. Here we aimed to investigate the prognostic and diagnostic impact of NLR, PLR, and Fibrinogen in patients with thymic epithelial tumors (TETs).

Results: Pretreatment Fibrinogen serum concentrations, NLRs and PLRs were highest in patients with TCs and advanced tumor stages. High pretreatment Fibrinogen serum concentration ( $\geq 452.5 \mathrm{mg} / \mathrm{dL}$ ) was significantly associated with worse cause specific survival (CSS; $p=0.001$ ) and freedom from recurrence (FFR; $p=0.043$ ), high NLR $(\geq 4.0)$ with worse FFR $(p=0.008)$, and high PLR $(\geq 136.5)$ with worse CSS $(p=0.032)$. Longitudinal analysis revealed that compared to patients without tumor recurrence, patients with tumor recurrence had significantly higher NLR $(11.8 \pm 4.0$ vs. $4.70 \pm 0.5 ; p=0.001)$ and PLR $(410.8 \pm 149.1$ vs. $228.3 \pm 23.7 ; p=0.031)$.

Conclusion: Overall, Fibrinogen serum concentrations, NLRs, and PLRs were associated with higher tumor stage, more aggressive tumor behavior, recurrence, and worse outcome. Prospective multicenter studies of the diagnostic and prognostic potential of Fibrinogen, NLR, and PLR are warranted.

Methods: This retrospective analysis included 122 patients with TETs who underwent surgical resection between 1999-2015. Fibrinogen serum concentrations, NLRs, and PLRs were measured in patients preoperatively, postoperatively, and later during follow-up. These markers were analyzed for association with several clinical variables, including tumor stage, tumor subtype, FFR, and CSS and to evaluate their prognostic and diagnostic impact for detecting tumor recurrence. 


\section{INTRODUCTION}

Thymic epithelial tumors (TETs) are intrathoracic malignancies that, although rare, represent the most common anterior mediastinal tumors in adults. TETs show a unique association with the autoimmune disorder Myasthenia Gravis (MG). According to the WHO classification, TETs are histologically subdivided into A, $\mathrm{AB}, \mathrm{B} 1, \mathrm{~B} 2$, and $\mathrm{B} 3$ thymomas (and other rare subtypes) and thymic carcinomas (TCs) [1]. The Masaoka-Koga staging system has been used to pathologically grade TETs as stage I to IV depending on their level of invasiveness [2]. However, the International Thymic Malignancy Interest Group (ITMIG) recently proposed the use of the eighth edition of the TNM staging classification system for TETs by the American Joint Committee on Cancer (AJCC) and the Union for International Cancer Control (UICC), which might replace the currently accepted Masaoka-Koga staging system [3-6].

For advanced TETs, the mainstay of treatment is surgical tumor resection combined with multimodal therapy, which results in excellent 5- and 10-year overall survival (OS) rates of $96.5 \%$ and $90.9 \%$, respectively [7, 8]. However, up to $30 \%$ of cases exhibit tumor recurrence, potentially even decades after initial therapy, necessitating lifelong follow-up mandatory $[9,10]$. The lack of established and reliable biomarkers means that patients must undergo repeated chest computer tomography $(\mathrm{CT})$ scans $[8,11]$. Thus, there exists a need for affordable diagnostic and prognostic biomarkers.

We recently demonstrated that increased serum concentrations of C-reactive protein (CRP), heat shock proteins (HSPs), and high-mobility group box-1 (HMGB1) were associated with advanced tumor stage and worse outcome [7, 12, 13]. CRP monitoring is inexpensive, and CRP is currently assessed as a routinely measured marker for TET detection [14]. Each of the above-mentioned molecules is reportedly linked to inflammation and malignancies [15-17], with inflammatory responses playing crucial roles in various stages of tumor development, including tumor initiation, progression, and metastasis [18-21]. Peripheral bloodderived inflammation-based markers, such as CRP, Fibrinogen, the neutrophil-to-lymphocyte ratio (NLR), and the platelet-to-lymphocyte ratio (PLR) have been widely investigated and identified as prognostic markers in various solid tumors [22-25].

To date, only one study has investigated the roles of pretreatment NLR and PLR in patients with TCs, demonstrating that high pretreatment NLR was associated with larger tumor size and worse outcome [26]. However, no studies have examined the prognostic and diagnostic impact of NLR and PLR in thymomas, and their reliability in predicting tumor recurrence remains unknown. Furthermore, the role of Fibrinogen has not yet been elucidated in patients with TETs. In the present study, our primary aim was to assess the prognostic and diagnostic value of Fibrinogen serum concentration, NLR, and PLR in patients with TETs. We further evaluated whether lymphocytes, neutrophils, and platelets differed according to tumor subtype, tumor stage, or paraneoplastic MG. Finally, we evaluated the potential Fibrinogen expression in neoplastic thymic epithelial cells.

\section{RESULTS}

\section{Patient cohort}

For this study, we recruited a total of 122 patients, including $52(42.6 \%)$ males and $70(57.4 \%)$ females, with a mean age of $56.5 \pm 16.1$ years. Histological analysis revealed that the vast majority of patients presented with thymomas ( $n=92 ; 75.4 \%$ ), with the most common subtypes being B2 (19.7\%) and AB (14.8\%). The remaining 30 patients $(24.6 \%)$ were diagnosed with TCs, with 29 patients having thymic squamous cell carcinomas (SCCs) and 1 having thymic adenocarcinoma of the enteric subtype. At time of diagnosis, $69.6 \%$ of patients presented with early Masaoka-Koga tumor stage (Stage I-II), with a mean tumor size of $58.5 \pm 29.3 \mathrm{~mm}$. Paraneoplastic MG was diagnosed in $26.2 \%$ of patients.

Among the cases, $45.9 \%$ were treated with surgical tumor resection alone, while $54.1 \%$ underwent multimodal treatment regimens combining surgery with radiotherapy and/or chemotherapy. Neoadjuvant therapy was performed in $18.8 \%$ of patients, and adjuvant therapy in $43.4 \%$. Chemotherapy was mainly used in neoadjuvant settings, while radiotherapy was predominantly used in adjuvant settings. Radical tumor resection (R0) was achieved in $89.3 \%$ of cases.

\section{Preoperative Fibrinogen, NLR, and PLR in patients with TETs}

Preoperative serum Fibrinogen, NLR, and PLR values were available in 112, 102, and 95 patients, respectively. Age and sex had no significant influence on Fibrinogen levels ( $p=0.201$ and $p=0.586$, respectively), NLR $(p=0.888$ and $p=0.419$, respectively), or PLR ( $p=0.715$ and $p=0.976$, respectively). Fibrinogen serum concentrations were significantly higher in patients with TETs $(390.2 \pm 11.4 \mathrm{mg} / \mathrm{dL})$ compared to healthy volunteers $(314.8 \pm 10.7 \mathrm{mg} / \mathrm{dL} ; p<0.001)$. Moreover, Fibrinogen levels were significantly higher in patients with TCs $(469.4 \pm 30.9 \mathrm{mg} / \mathrm{dL})$ compared to patients with thymomas $(363.8 \pm 9.7 \mathrm{mg} / \mathrm{dL} ; p=0.003)$. We also detected significantly elevated NLR and PLR in patients with TETs $(3.4 \pm 0.3$ and $179.8 \pm 12.1$, respectively) compared to controls $(1.8 \pm 0.1$ and $133.4 \pm 7.1 ; p<0.001$ and $p=0.001$, respectively). Similarly to Fibrinogen, the mean NLR and PLR values were significantly higher in patients with TCs $(5.1 \pm 0.8$ and $268.2 \pm 37.0$, 
respectively) than in patients with thymomas $(3.0 \pm 0.2$ and $154.8 \pm 9.8 ; p=0.020$ and 0.007 , respectively).

\section{Thymoma subtypes according to the WHO classification}

According to WHO classification, Fibrinogen serum concentrations were lowest in patients with micronodular thymoma with lymphoid stroma (MNT) $(331.7 \pm 34.3 \mathrm{mg} / \mathrm{dL})$ and those with $\mathrm{AB}$ thymomas $(341.5 \pm 26.0 \mathrm{mg} / \mathrm{dL})$. NLR and PLR values were lowest in patients with B1 thymomas (2.19 \pm 0.15 and $110.7 \pm 15.0$, respectively) and B2 thymomas ( $2.70 \pm 0.4$ and $124.5 \pm 13.7$, respectively; Table 1). Nonetheless, there were no significant differences between thymoma histotypes according to Fibrinogen serum concentrations $(p=0.418)$, NLR $(p=0.513)$ and PLR $(p=0.158)$, respectively.

\section{Masaoka-koga tumor stage}

Compared to patients with early stage tumors (stage I-II), those with advanced stage tumors (stage III-IV) had significantly higher Fibrinogen levels $(457.0 \pm 26.8 \mathrm{mg} /$ dL vs. $361.0 \pm 9.9 \mathrm{mg} / \mathrm{dL} ; p=0.002), \operatorname{NLR}(4.54 \pm 0.7$ vs. $3.01 \pm 0.2 ; p=0.040)$ and PLR $(247.6 \pm 32.1$ vs. $152.9 \pm 9.5 ; p=0.008$ ) (Table 1). Interestingly, Fibrinogen serum concentrations gradually increased with the level of invasiveness, with serum levels of $354.5 \pm 13.0 \mathrm{mg} / \mathrm{dL}$ in non-invasive stage I tumors and $470.8 \pm 35.3 \mathrm{mg} / \mathrm{dL}$ in stage IV TETs (Figure 1A).

Comparison of early stage thymomas (stages I-II) vs. advanced stage thymomas (stage III-IV) showed no significant differences in Fibrinogen serum concentrations $(360.4 \pm 10.3 \mathrm{mg} / \mathrm{dL}$ vs. $383.9 \pm 29.3 \mathrm{mg} / \mathrm{dL} ; p=0.400)$, $\operatorname{NLR}(2.95 \pm 0.22$ vs. $3.17 \pm 0.70 ; p=0.730)$, or PLR $(150.7 \pm 10.1$ vs. $177.9 \pm 33.1 ; p=0.328)$. Similarly, comparison of early stage TCs (stage I-II) vs. advanced stage TCs (stage III-IV) showed no significant differences in Fibrinogen $(368.5 \pm 41.3 \mathrm{mg} / \mathrm{dL}$ vs. $496.9 \pm 35.8 \mathrm{mg} / \mathrm{dL}$; $p=0.088)$, NLR ( $3.90 \pm 1.44$ vs. $5.43 \pm 1.0 ; p=0.447)$, or PLR $(180.7 \pm 23.7$ vs. $295.5 \pm 46.3 ; p=0.194)$.

\section{Paraneoplastic MG}

MG was diagnosed in $32(26.2 \%)$ of the 122 patients, including in $45.8 \%$ of B2 thymomas (11 out of 24 ) and $41.2 \%$ of B3 thymomas (7 out of 17). Among these 32 patients, preoperative Fibrinogen, NLR, and PLR values were available for 31,27 , and 26 , respectively. Compared to MG-positive patients, MG-negative patients had significantly higher preoperative Fibrinogen serum concentrations $(404.9 \pm 124.4 \mathrm{mg} / \mathrm{dL}$ vs. $351.8 \pm$ $102.3 \mathrm{mg} / \mathrm{dL} ; p=0.037)$ and tumor size $(6.1 \pm 3.1 \mathrm{~cm}$ vs. $4.5 \pm 2.9 \mathrm{~cm} ; p=0.049)$. However, after exclusion of TCs, the difference in Fibrinogen serum concentration between MG-negative and MG-positive thymomas was not significant $(377.5 \pm 13.0 \mathrm{mg} / \mathrm{dL}$ vs. $337.7 \pm 12.5$ $\mathrm{mg} / \mathrm{dL} ; p=0.051)$. NLR and PLR did not significantly differ according to MG status ( $p=0.455$ and $p=0.356$, respectively).

The majority of MG patients (63.2\%) received therapy with acetylcholinesterase inhibitors as single therapy or in combination with azathioprine $(21.1 \%)$ or corticosteroids (26.4\%). Myasthenic patients treated with acetylcholinesterase inhibitors alone compared to those treated with additive immunosuppressive regimens did not significantly differ in Fibrinogen level $(342.7 \pm 75.5 \mathrm{mg} /$ dL vs. $330.4 \pm 76.7 \mathrm{mg} / \mathrm{dL} ; p=0.739)$, NLR $(1.96 \pm 0.8$ vs. $4.38 \pm 3.2 ; p=0.164)$, or PLR $(105.0 \pm 28.3$ vs. 165.5 $\pm 87.9 ; p=0.052$ ).

\section{Neutrophil, lymphocyte, and platelet blood counts in patients with TETs}

We next evaluated how neutrophil, lymphocyte, and platelet blood counts were associated with clinical characteristics, including WHO classification, MasaokaKoga tumor stage, and paraneoplastic MG. Absolute and relative neutrophil and lymphocyte counts and absolute platelet counts did not significantly differ according to WHO classification or Masaoka-Koga tumor stage (Table 2). Although this difference was not significant, absolute lymphocyte numbers gradually decreased with level of invasiveness, from $1.98 \pm 0.80 \mathrm{G} / \mathrm{L}$ at noninvasive stage I to $1.43 \pm 0.70 \mathrm{G} / \mathrm{L}$ at metastasized stage IV $(p=0.822$; Figure 1B). We observed the highest lymphocyte levels in patients with B1 and B2 thymomas, and the lowest levels in TCs. Absolute lymphocyte numbers were significantly higher in patients with paraneoplastic MG $(2.09 \pm 0.7 \mathrm{G} / \mathrm{L})$ compared to MG-negative patients $(1.69 \pm 0.1 \mathrm{G} / \mathrm{L} ; p=0.020)$, while neutrophil, platelet, and relative lymphocyte numbers did not significantly differ between these two patient groups (Table 2).

\section{Prognostic analysis: survival and recurrence}

Median follow-up time was 30.8 months (mean, 40.8 months). Of the 122 patients, 15 (12.3\%) experienced recurrence, including 3 local $(2.5 \%)$, 4 regional $(3.3 \%)$, and 8 distant $(6.6 \%)$ recurrences. We performed survival analyses to determine how freedom from recurrence (FFR) and cause specific survival (CSS) were impacted by pretreatment serum Fibrinogen concentration, NLR, and PLR. By calculating the Youden Index, we identified $452.5 \mathrm{mg} / \mathrm{dL}$ as an optimal cut-off value for discriminating between low and high Fibrinogen. To dichotomize patients into low and high NLR and PLR subgroups, we used an empiric cut-off value of 4.0 and a median of 136.5, respectively. High Fibrinogen was associated with significantly worse FFR $(p=0.043)$ and CSS $(p=0.001)$. Patients with high NLR showed significantly worse FFR $(p=0.008)$, while patients with high PLR showed significantly worse CSS ( $p=0.032$; Figure 2$)$. 
Table 1: Preoperative analysis of Fibrinogen, NLR, and PLR in thymic epithelial tumors

\begin{tabular}{|c|c|c|c|c|c|c|c|c|c|}
\hline \multirow{2}{*}{ Characteristics } & \multirow{2}{*}{$n$} & Fibrinogen & \multirow{2}{*}{ p-value } & \multirow{2}{*}{$n$} & NLR & \multirow{2}{*}{ p-value } & \multirow{2}{*}{$n$} & PLR & \multirow{2}{*}{ p-value } \\
\hline & & mean $($ median $) \pm S D(S E M)$ & & & mean $($ median $) \pm S D(S E M)$ & & & mean $($ median $) \pm S D(S E M)$ & \\
\hline TETs & 112 & $390.2(360.5) \pm 120.6(11.4)$ & & 102 & $3.43(2.64) \pm 2.59(0.3)$ & & 95 & $179.8(142.4) \pm 118.0(12.1)$ & \\
\hline Controls & 27 & $314.8(315.0) \pm 56.5(10.9)$ & $<0.001^{\mathrm{a}}$ & 51 & $1.78(1.63) \pm 0.75(0.1)$ & $<0.001^{\mathrm{a}}$ & 48 & $133.4(124.4) \pm 49.4(7.1)$ & $0.001^{\mathrm{a}}$ \\
\hline \multicolumn{10}{|l|}{ Age (years) } \\
\hline$<57$ & 54 & $375.0(328.5) \pm 121.3(16.5)$ & & 48 & $3.47(2.49) \pm 2.79(0.40)$ & & 44 & $184.7(150.0) \pm 107.2(16.2)$ & \\
\hline$\geq 57$ & 58 & $404.3(370.5) \pm 119.3(15.7)$ & $0.201^{\mathrm{a}}$ & 54 & $3.40(2.86) \pm 2.42(0.33)$ & $0.888^{\mathrm{a}}$ & 51 & $175.7(142.0) \pm 127.4(17.8)$ & $0.715^{\mathrm{a}}$ \\
\hline \multicolumn{10}{|l|}{ Sex } \\
\hline Male & 46 & $397.6(369.5) \pm 139.5(20.6)$ & & 40 & $3.69(2.92) \pm 2.41(0.38)$ & & 37 & $180.3(138.7) \pm 99.2(16.3)$ & \\
\hline Female & 66 & $384.9(353.0) \pm 106.3(13.1)$ & $0.586^{\mathrm{a}}$ & 62 & $3.27(2.53) \pm 2.71(0.34)$ & $0.419^{\mathrm{a}}$ & 58 & $179.5(150.0) \pm 129.3(17.0)$ & $0.976^{\mathrm{a}}$ \\
\hline \multicolumn{10}{|l|}{ WHO } \\
\hline MNT & 7 & $331.7(327.0) \pm 90.8(34.3)$ & & 7 & $5.10(2.42) \pm 3.81(1.44)$ & & 7 & $252.6(274.4) \pm 142.3(53.8)$ & \\
\hline A & 14 & $405.2(385.5) \pm 82.0(21.9)$ & & 14 & $3.32(3.04) \pm 2.04(0.59)$ & & 12 & $198.8(167.8) \pm 89.6(25.9)$ & \\
\hline $\mathrm{AB}$ & 16 & $341.5(315.5) \pm 104.1(26.0)$ & & 16 & $2.93(2.97) \pm 0.82(0.21)$ & & 14 & $140.7(126.3) \pm 59.0(15.8)$ & \\
\hline B1 & 10 & $361.9(358.5) \pm 54.8(17.3)$ & & 10 & $2.19(0.18) \pm 0.49(0.15)$ & & 10 & $110.7(83.8) \pm 47.3(15.0)$ & \\
\hline B2 & 22 & $364.7(351.5) \pm 87.8(18.7)$ & & 22 & $2.70(2.47) \pm 1.89(0.42)$ & & 18 & $124.5(108.6) \pm 58.1(13.7)$ & \\
\hline B3 & 15 & $363.5(334.0) \pm 96.9(25.0)$ & & 15 & $2.71(2.53) \pm 1.47(0.39)$ & & 13 & $152.4(139.5) \pm 71.3(19.8)$ & \\
\hline $\mathrm{TC}$ & 28 & $469.4(473.0) \pm 163.4(30.9)$ & $0.003^{\mathrm{b}}$ & 28 & $5.09(4.05) \pm 3.84(0.82)$ & $0.005^{b}$ & 21 & $268.2(230.0) \pm 169.6(37.0)$ & $<0.001^{\mathrm{b}}$ \\
\hline \multicolumn{10}{|l|}{ Tumor Stage I } \\
\hline I & 25 & $354.5(346.0) \pm 65.1(13.0)$ & & 25 & $2.84(2.44) \pm 1.69(0.36)$ & & 20 & $171.3(163.6) \pm 74.4(16.7)$ & \\
\hline II & 53 & $364.1(352.0) \pm 96.9(13.3)$ & & 53 & $3.09(2.69) \pm 2.08(0.29)$ & & 48 & $145.3(129.4) \pm 79.3(11.5)$ & \\
\hline III & 11 & $428.1(415.0) \pm 126.5(38.1)$ & & 11 & $4.74(4.10) \pm 3.88(1.29)$ & & 9 & $268.9(281.4) \pm 145.5(48.5)$ & \\
\hline IV & 23 & $470.8(465.0) \pm 169.3(35.3)$ & $0.001^{\mathrm{b}}$ & 23 & $4.45(3.22) \pm 3.54(0.81)$ & $0.061^{\mathrm{b}}$ & 18 & $236.9(173.0) \pm 179.7(42.4)$ & $0.003^{b}$ \\
\hline \multicolumn{10}{|l|}{ Tumor Stage II } \\
\hline Early I-II & 78 & $361.0(349.5) \pm 87.7(9.93)$ & & 74 & $3.01(2.61) \pm 1.97(0.23)$ & & 68 & $152.9(135.6) \pm 78.3(9.49)$ & \\
\hline Advanced III-IV & 34 & $457.0(463.0) \pm 156.1(26.8)$ & $0.002^{\mathrm{b}}$ & 28 & $4.54(3.31) \pm 3.58(0.68)$ & $0.040^{\mathrm{b}}$ & 27 & $247.6(177.1) \pm 166.9(32.1)$ & $0.008^{\mathrm{b}}$ \\
\hline \multicolumn{10}{|c|}{ Myasthenia Gravis } \\
\hline Yes & 31 & $351.8(330.0) \pm 102.3(18.4)$ & & 31 & $3.11(2.40) \pm 2.75(0.53)$ & & 26 & $161.5(133.5) \pm 148.4(29.1)$ & \\
\hline No & 81 & $404.8(368.0) \pm 124.5(13.8)$ & $0.037^{\mathrm{a}}$ & 81 & $3.55(2.83) \pm 2.54(0.29)$ & $0.455^{\mathrm{a}}$ & 69 & $186.7(158.8) \pm 104.7(12.6)$ & $0.356^{\mathrm{a}}$ \\
\hline
\end{tabular}

Preoperative Fibrinogen serum values, NLR and PLR are shown with regards to sex, age, WHO classification, tumor stage and Myasthenia Gravis. Data are indicates as mean (median) \pm SD (SEM). NLR, Neutrophil-to-Lymphocyte Ratio; PLR, Platelet-to-Lymphocyte Ratio; SD, standard deviation; SEM, standard error of the mean; TETs, Thymic Epithelial Tumors; WHO, World Health Organization classification of histologic tumor subtype. ${ }^{a}$ unpaired Student's $t$-test; ${ }^{\mathrm{b}}$ one-way ANOVA.
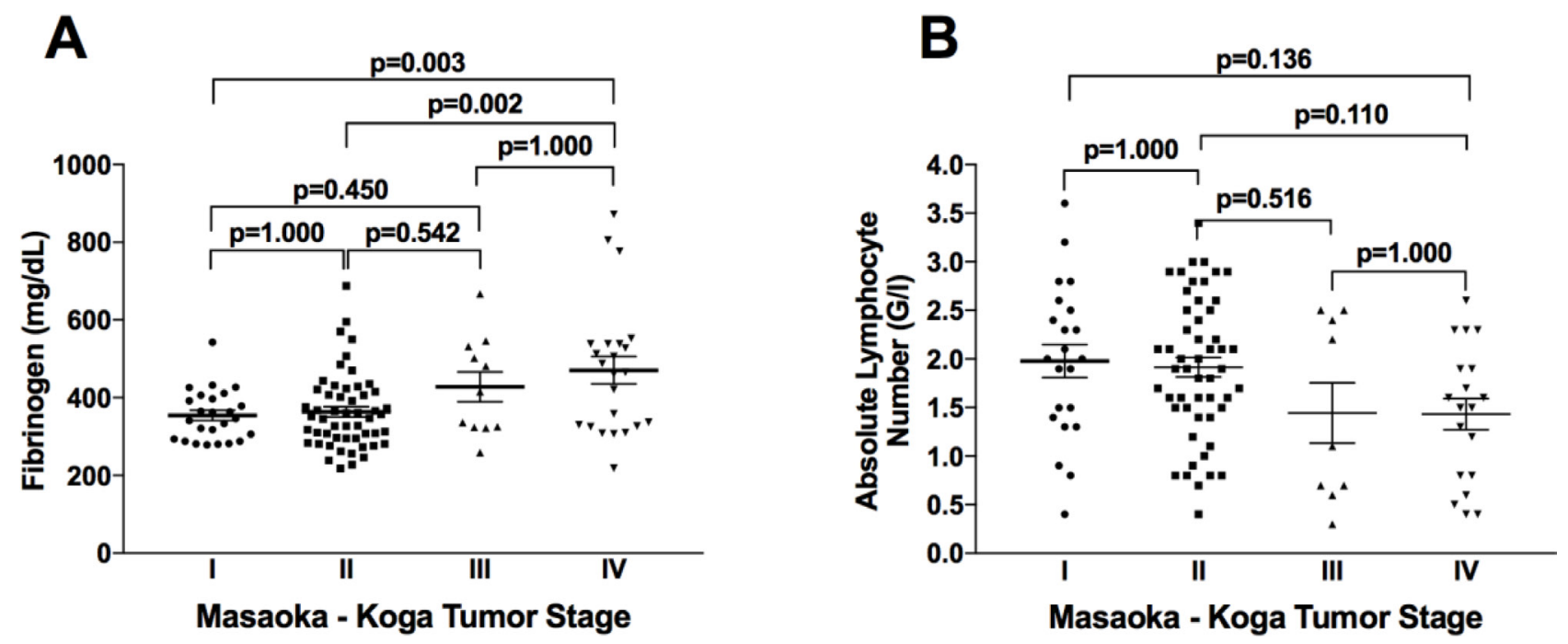

Figure 1: Fibrinogen and absolute lymphocyte numbers according to clinical Masaoka-Koga tumor stage. Fibrinogen serum concentrations gradually increased with invasiveness level (A). Peripheral blood absolute lymphocyte numbers gradually decreased with tumor stage (B). 
Table 2: Neutrophil, lymphocyte, and platelet numbers according to clinical characteristics of patients with TETs

\begin{tabular}{|c|c|c|c|c|c|c|}
\hline & Neutrophils & & Lymphocytes & & Platelets & \\
\hline & abs. (rel.) & $p$-value & abs. (rel.) & $p$-value & abs. & p-value \\
\hline \multicolumn{7}{|l|}{ WHO } \\
\hline MNT & $4.53(70.40 \%)$ & & $1.34(20.6 \%)$ & & 252.3 & \\
\hline A & $3.19(64.6 \%)$ & & $1.53(24.0 \%)$ & & 286.5 & \\
\hline $\mathrm{AB}$ & $4.52(66.3 \%)$ & & $1.82(24.2 \%)$ & & 243.7 & \\
\hline B1 & $4.73(60.2 \%)$ & & $2.35(31.1 \%)$ & & 235.0 & \\
\hline B2 & $4.32(62.4 \%)$ & & $2.23(28.7 \%)$ & & 272.1 & \\
\hline B3 & $3.78(62.6 \%)$ & & $1.96(27.5 \%)$ & & 280.9 & \\
\hline $\mathrm{TC}$ & $3.50(68.6 \%)$ & $0.820(0.230)^{\mathrm{a}}$ & $1.30(19.8 \%)$ & $0.958(0.065)^{\mathrm{a}}$ & 279.1 & $0.166^{\mathrm{a}}$ \\
\hline \multicolumn{7}{|c|}{ Tumor Stage } \\
\hline I & $3.70(63.6 \%)$ & & $1.98(27.1 \%)$ & & 299.5 & \\
\hline II & $4.47(64.3 \%)$ & & $1.92(25.8 \%)$ & & 249.7 & \\
\hline III & $3.49(67.5 \%)$ & & $1.44(21.1 \%)$ & & 266.8 & \\
\hline IV & $3.43(67.2 \%)$ & $0.986(0.262)^{\mathrm{a}}$ & $1.43(22.6 \%)$ & $0.822(0.076)^{\mathrm{a}}$ & 277.1 & $0.676^{\mathrm{a}}$ \\
\hline \multicolumn{7}{|l|}{ MG } \\
\hline Yes & $4.25(63.4 \%)$ & & $2.09(27.1 \%)$ & & 273.4 & \\
\hline No & $3.89(65.5 \%)$ & $0.458(0.352)^{\mathrm{b}}$ & $1.69(24.3 \%)$ & $0.020(0.200)^{\mathrm{b}}$ & 266.5 & $0.753^{b}$ \\
\hline
\end{tabular}

Data are presented as mean absolute (abs.; G/L) and relative (rel.; \%) numbers of neutrophils and lymphocytes, and absolute (abs., G/L) number of platelets. TETs, Thymic epithelial tumors; WHO, World Health Organization classification of histologic tumor subtype; MG, Myasthenia Gravis; MNT, micronodular thymoma; TC, thymic carcinoma. ${ }^{\mathrm{a}}$ One-way ANOVA; ${ }^{\text {b }}$ unpaired Student's $t$-test.

In separate analyses of thymomas and TCs, we found that high pretreatment Fibrinogen serum levels were associated with significantly worse CSS in patients with thymomas $(p=0.013)$, but not in patients with TCs $(p=0.119)$. On the other hand, FFR did not significantly differ in relation to Fibrinogen in either subgroup ( $p=0.880$ and $p=0.696$ ). Pretreatment NLR and PLR values did not significantly affect CSS or FFR in patients with thymomas (CSS: $p=0.717$ and $p=0.202$, respectively; FFR: $p=0.572$ and $p=0.792$, respectively) or in patients with TCs (CSS: $p=0.506$ and $p=0.526$, respectively; FFR: $p=0.374$ and $p=0.967$, respectively).

We additionally performed univariable and multivariable Cox-regression analyses to assess the prognostic power of clinical characteristics, including histology (TC vs. thymoma), Masaoka-Koga tumor stage (early stage I-II vs. advanced stage III-IV), Fibrinogen (high vs. low), NLR (high vs. low), and PLR (high vs. low), with regards to FFR and CSS. Univariable analysis revealed that significantly worse FFR was associated with presence of TC (HR 4.93; $p=0.002)$ and high pretreatment NLR (HR 3.95; $p=0.014$ ) but not with Masaoka-Koga tumor stage, PLR, or Fibrinogen. In multivariable analysis, only diagnosis of TC remained a significant and strong predictor of worse FFR (HR 8.55; $p=0.036)$. Conversely, worse CSS was associated with TC (HR 23.3; $p=0.004$ ), advanced tumor stage
(HR 12.35; $p=0.022$ ) and high Fibrinogen (HR 17.24; $p=0.012$ ) but not with high PLR or high NLR. None of the tested variables remained a significant prognostic factor for CSS in multivariable analysis (Table 3).

\section{Longitudinal analysis}

Next, we performed longitudinal analysis of the preoperative, postoperative ( 3 to 7 days after surgery) and follow-up (6 to 12 months after surgery) measurements of Fibrinogen serum concentration, NLR, and PLR to evaluate the reliability of these parameters as tumor markers within oncologic follow-up. Compared to healthy controls, patients with TETs had significantly higher mean preoperative Fibrinogen serum levels $(390.2 \pm 11.4 \mathrm{mg} /$ dL vs. $314.8 \pm 10.9 \mathrm{mg} / \mathrm{dL} ; p<0.001)$, NLR $(3.43 \pm$ 0.3 vs. $1.78 \pm 0.1 ; p=0.001)$, and PLR $(179.8 \pm 12.1$ vs. $133.4 \pm 7.1 ; p=0.001)$. Relative to the preoperative values, postoperative Fibrinogen serum concentrations and NLR values were significantly elevated in thymomas (Fibrinogen: $445.6 \pm 14.7 \mathrm{mg} / \mathrm{dL}$ vs. $364.7 \pm 9.8 \mathrm{mg} / \mathrm{dL}$; $p<0.001$; NLR: $6.22 \pm 0.5$ vs. $2.99 \pm 0.2 ; p<0.001$ ) and in TCs (Fibrinogen: $541.5 \pm 34.0 \mathrm{mg} / \mathrm{dL}$ vs. $469.4 \pm$ $30.9 \mathrm{mg} / \mathrm{dL} ; p=0.006$; NLR: $10.5 \pm 1.4$ vs. $5.1 \pm 0.8$; $p=0.007)$. At $6-12$ months after tumor resection, Fibrinogen and NLR were significantly decreased compared to postoperative values in thymomas 
A

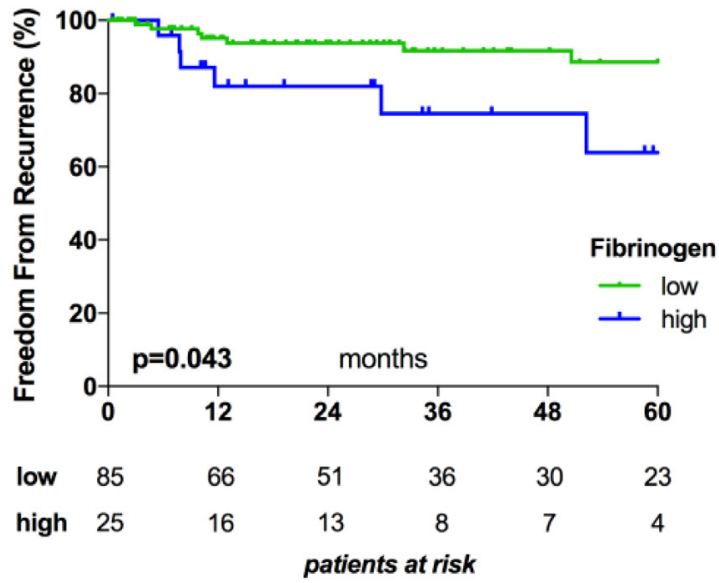

C
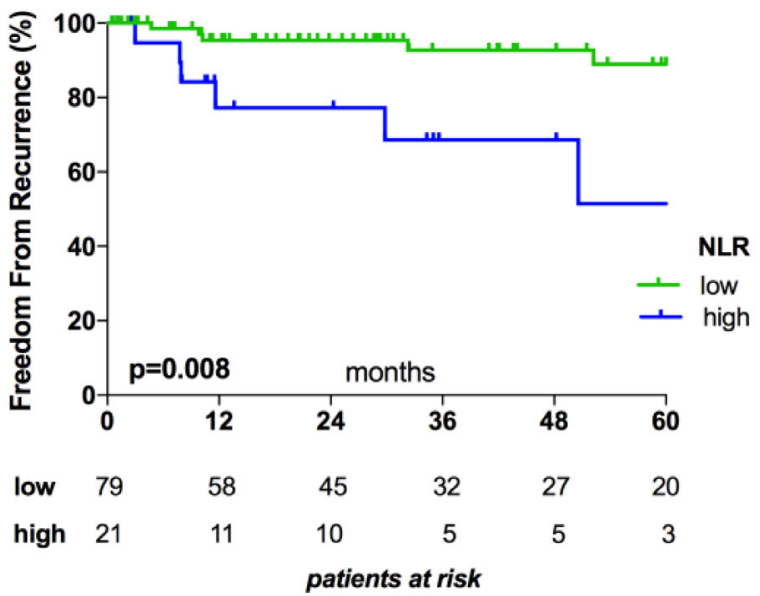

E

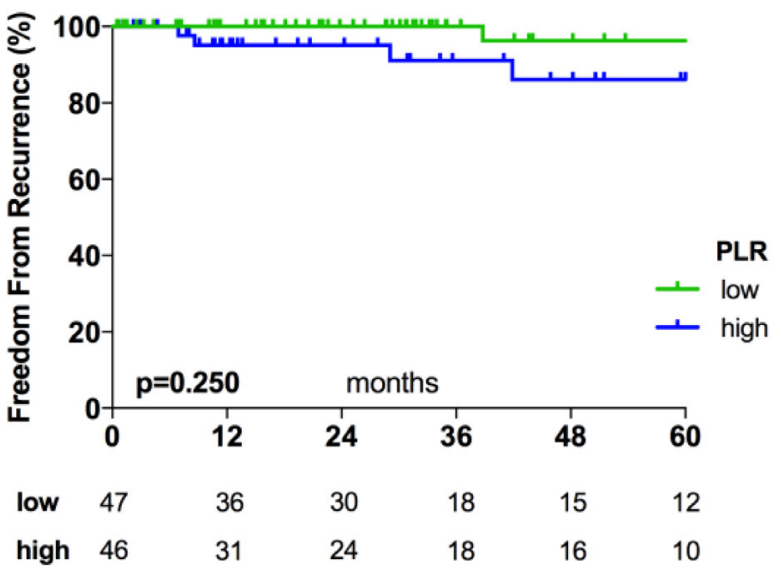

patients at risk
B

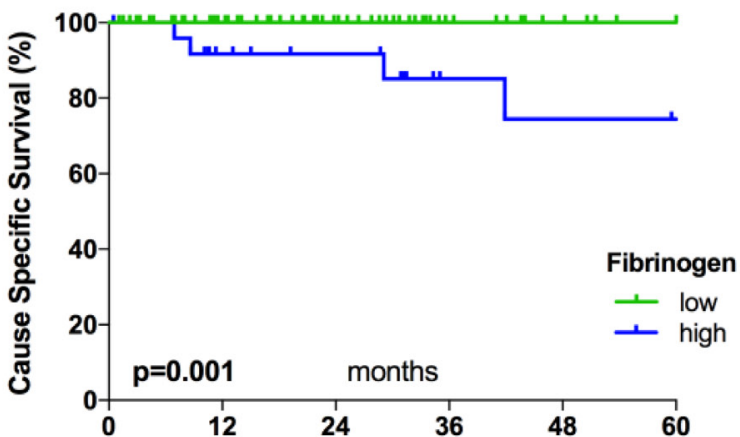

\begin{tabular}{ccccccc} 
low & 85 & 68 & 53 & 37 & 30 & 23 \\
high & 25 & 19 & 15 & 8 & 7 & 6 \\
& \multicolumn{5}{c}{ patients at risk }
\end{tabular}

D

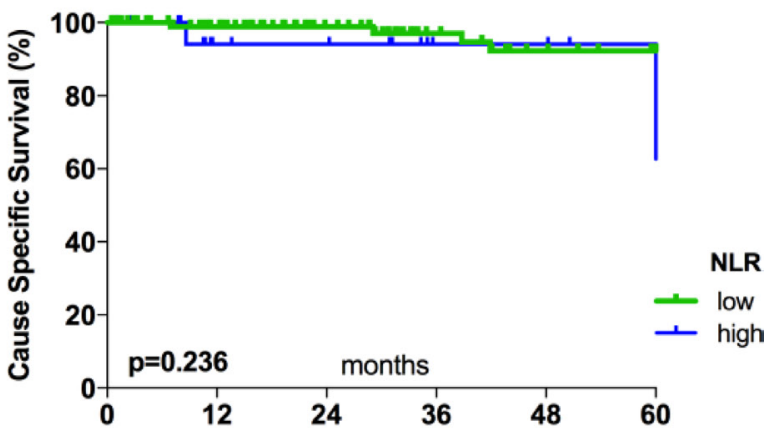

$\begin{array}{lllllll}\text { low } & 79 & 60 & 47 & 33 & 27 & 22\end{array}$

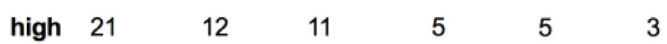

patients at risk

F

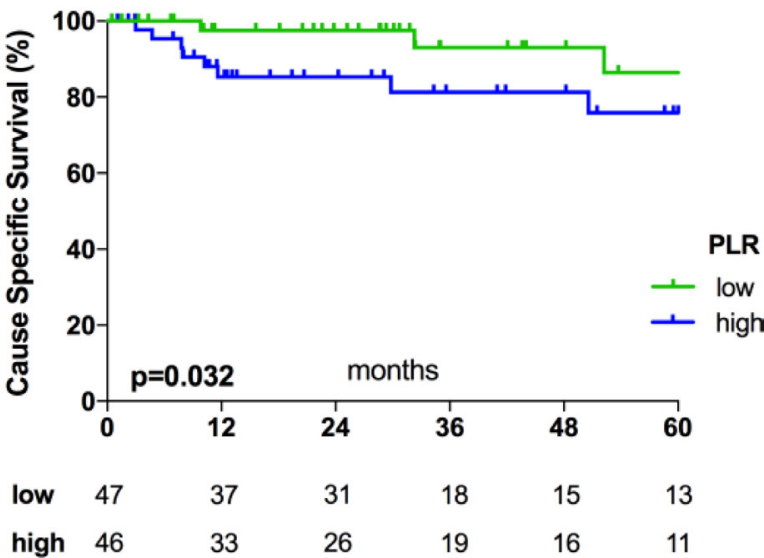

patients at risk

Figure 2: Kaplan-Meier survival curves for Fibrinogen, NLR, and PLR. Graphs show the associations between Fibrinogen and FFR (A) and CSS (B), between NLR and FFR (C) and CSS (D), and between PLR and FFR (E) and CSS (F). The cut-off values used to dichotomize patients into low and high subgroups were $452.5 \mathrm{mg} / \mathrm{dL}$ for Fibrinogen, 4.0 for NLR, and 136.5 for PLR. NLR, Neutrophilto-Lymphocyte Ratio; PLR, Platelet-to-Lymphocyte Ratio. 
Table 3: Univariable and multivariable Cox regression analysis

\begin{tabular}{lcccccc}
\hline & \multicolumn{3}{c}{ Univariable } & \multicolumn{3}{c}{ Multivariable } \\
\hline & HR & $p$-value & $\mathbf{9 5 \% ~ C I ~}$ & HR & $p$-value & $\mathbf{9 5 \% ~ C I ~}$ \\
\hline Freedom from recurrence & & & & & & \\
$\quad$ Histology (TC vs. Thymoma) & 4.93 & 0.002 & $1.76-13.7$ & 8.55 & 0.036 & $1.14-62.5$ \\
Tumor Stage (I-II vs. III-IV) & 2.60 & 0.066 & $0.94-7.14$ & 0.68 & 0.673 & $0.12-4.02$ \\
Fibrinogen (high vs. low) & 2.86 & 0.053 & $0.99-8.26$ & 1.40 & 0.601 & $0.40-4.95$ \\
NLR (high vs. low) & 3.95 & 0.014 & $1.32-11.7$ & 3.14 & 0.145 & $0.67-14.7$ \\
PLR (high vs. low) & 2.00 & 0.259 & $0.60-6.67$ & 0.44 & 0.350 & $0.08-2.46$ \\
Cause specific survival & & & & & & \\
Histology (TC vs. Thymoma) & 23.3 & 0.004 & $2.68-200.0$ & 3.56 & 0.442 & $0.14-90.9$ \\
Tumor Stage (I-II vs. III-IV) & 12.35 & 0.022 & $1.43-11.1$ & 3.10 & 0.459 & $0.16-62.5$ \\
Fibrinogen (high vs. low) & 17.24 & 0.012 & $1.87-166.7$ & 9.09 & 0.149 & $0.45-166.7$ \\
$\quad$ NLR (high vs. low) & 62.5 & 0.265 & $0.04-100.0$ & 0.61 & 0.677 & $0.06-6.10$ \\
PLR (high vs. low) & 2.83 & 0.257 & $0.47-16.5$ & 1.07 & 0.963 & $1.00-1.60$ \\
\hline
\end{tabular}

Presented data indicate the prognostic impact of tested factors. Patients were dichotomized into high and low subgroups using cut-off values of $452.5 \mathrm{mg} / \mathrm{dL}$ for Fibrinogen, 4.0 for NLR, and 136.5 for PLR. TC, Thymic carcinoma; HR, Hazard Ratio; CI, Confidence Interval; NLR, Neutrophil-to-Lymphocyte Ratio; PLR, Platelet-to-Lymphocyte Ratio.

(Fibrinogen: $356.5 \pm 25.2 \mathrm{mg} / \mathrm{dL}$ vs. $445.6 \pm 14.7 \mathrm{mg} / \mathrm{dL}$; $p=0.043$; NLR: $4.37 \pm 0.5$ vs. $6.22 \pm 0.5 ; p=0.004)$ but were not significantly reduced in TCs (Fibrinogen: $454.3 \pm 40.5 \mathrm{mg} / \mathrm{dL}$ vs. $541.5 \pm 34.0 \mathrm{mg} / \mathrm{dL} ; p=0.635$; NLR: $8.7 \pm 2.0$ vs. $10.5 \pm 1.4 ; p=0.657$ ). In patients with TCs, follow-up NLR values were significantly higher than preoperative values $(8.7 \pm 2.0$ vs. $5.1 \pm 0.8 ; p=0.028)$, while Fibrinogen levels did not significantly differ (454.3 $\pm 40.5 \mathrm{mg} / \mathrm{dL}$ vs. $469.4 \pm 30.9 \mathrm{mg} / \mathrm{dL} ; p=0.478)$. In thymoma patients, follow-up Fibrinogen levels and NLR values were similar to preoperative values (Fibrinogen: $356.5 \pm 25.2 \mathrm{mg} / \mathrm{dL}$ vs. $364.7 \pm 9.8 \mathrm{mg} / \mathrm{dL} ; p=0.931$; NLR: $4.37 \pm 0.5$ vs. $2.99 \pm 0.2 ; p=0.203$ ) (Figure $3 \mathrm{~A}$, 3B, 3D, 3E).

We found divergent trends for PLR values in thymomas and TCs. Compared to preoperative values, postoperative PLR was significantly elevated in patients with thymomas $(141.4 \pm 9.8$ vs. $156.9 \pm 10.1$; $p=0.014)$ but was decreased in patients with TCs $(207.8$ \pm 29.3 vs. $168.2 \pm 37.0 ; p=0.546)$. Nonetheless, we detected the highest PLR values for thymomas $(212.5 \pm$ $24.8)$ and TCs $(347.1 \pm 74.0)$ during oncologic follow-up (Figure $3 \mathrm{G}, 3 \mathrm{H}$ ).

Interestingly, separate analyses of patients with and without tumor recurrence revealed that patients with tumor recurrence showed significantly higher NLR ( $p=$ $0.001)$ and PLR $(p=0.031)$ at $6-12$ months post-resection (Figure 3F, 3I). In particular, compared to patients without tumor recurrence, patients with tumor recurrence showed significantly lower absolute and relative lymphocyte numbers ( $p=0.014$ and $p=0.027$, respectively), while platelet and neutrophil counts were slightly but not significantly higher ( $p=0.492$ and $p=0.154$, respectively).
In contrast, Fibrinogen serum concentrations did not significantly differ in patients with recurrence compared to those without ( $p=0.351$; Figure $3 \mathrm{C}$ ).

\section{NLR and PLR as prognostic markers during oncologic follow-up}

We further evaluated the reliability of NLR and PLR as markers for the prediction of tumor recurrence during oncologic follow-up. We performed ROC analysis of both markers for predicting tumor recurrence (Figure 4). The area under the curve (AUC) was 0.819 for NLR and 0.787 for PLR, indicating that both markers had high accuracy to predict tumor recurrence.

Next, we calculated Youden Indices to define the optimal NLR and PLR cut-off values for predicting tumor recurrence. The highest Youden Indices (0.574 and 0.581, respectively) were found at cut-off values of 6.6 for NLR and 202.5 for PLR. Using a NLR value of 6.6 as a cut-off to predict tumor recurrence, we achieved a sensitivity of $80 \%$, specificity of $77.4 \%$, positive predictive value (PPV) of 36.4, and negative predictive value (NPV) of $96 \%$. Using a PLR value of 202.5 as a cut-off, we achieved a sensitivity of $100 \%$, specificity of $58.1 \%$, PPV of $27.8 \%$, and NPV of $100 \%$.

Binary logistic regression analysis revealed that NLR was a significant factor for predicting tumor recurrence ( $\left.p=0.043 ; \mathrm{R}^{2}: 0.378\right)$, while PLR $(p=0.078$; $\left.\mathrm{R}^{2}: 0.165\right)$ and Fibrinogen $\left(p=0.341 ; \mathrm{R}^{2}: 0.054\right)$ were not. Moreover, we did not find an additive effect regarding prediction of tumor recurrence when using combinations of NLR and PLR (NLR: $p=0.046$; PLR: $p=0.847$; ${ }^{2}$ : $0.379)$, NLR and Fibrinogen (NLR: $p=0.071$; Fibrinogen: 
$p=0.913 ; \mathrm{R}^{2}: 0.369$ ), or PLR and Fibrinogen (PLR: $p=0.165$; Fibrinogen: $p=0.892 ; \mathrm{R}^{2}: 0.192$ ).

\section{Fibrinogen expression in TETs}

Finally, we performed immunohistochemical staining for Fibrinogen in representative B2/B3 thymomas to evaluate whether malignant thymic epithelial cells expressed Fibrinogen. Fibrinogen expression was detected on endothelial cells and within thrombotic clots, but was absent from neoplastic epithelial cells and cells of the hematopoietic lineage (Figure 5).

\section{DISCUSSION}

Chronic inflammation plays a pivotal role in carcinogenesis, and accumulating evidence indicates that systemic biomarkers that are upregulated in response to cancer-related inflammation (including CRP, Fibrinogen, NLR, and PLR) potentially have diagnostic and prognostic power in various malignancies. Here we investigated the possible prognostic and diagnostic impact of Fibrinogen, NLR, and PLR in patients with TETs.

The clinical and demographic characteristics of our study population, including female-to-male ratio, age, and percentages of TCs and $\mathrm{MG}$, were comparable to those in previous publications [9, 11, 27-29]. Within our cohort, high pretreatment Fibrinogen serum concentrations were associated with advanced tumor stage, and worse FFR and CSS. Notably, pretreatment Fibrinogen serum concentrations gradually increased from stage I to stage IV TETs, underlining the strong association between Fibrinogen and tumor invasiveness. With regards to WHO classification, Fibrinogen serum levels were
A

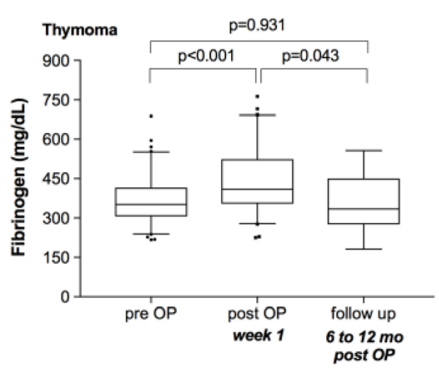

D

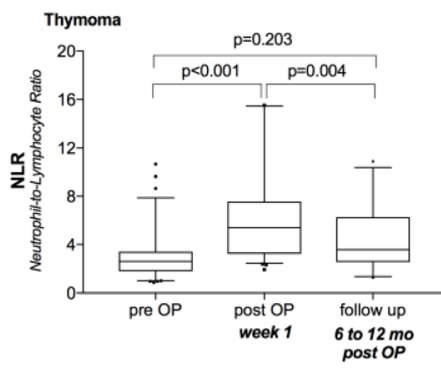

G

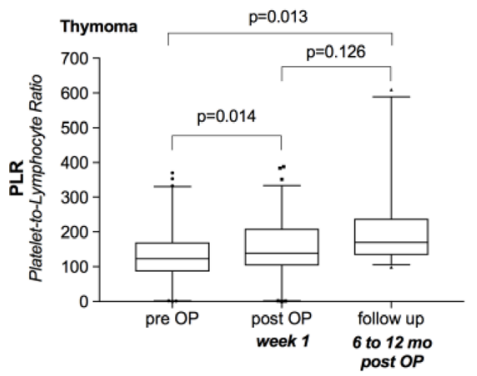

B

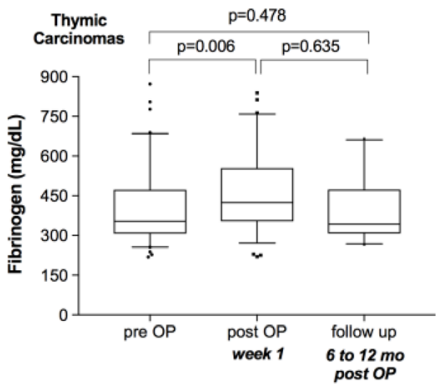

$\mathbf{E}$
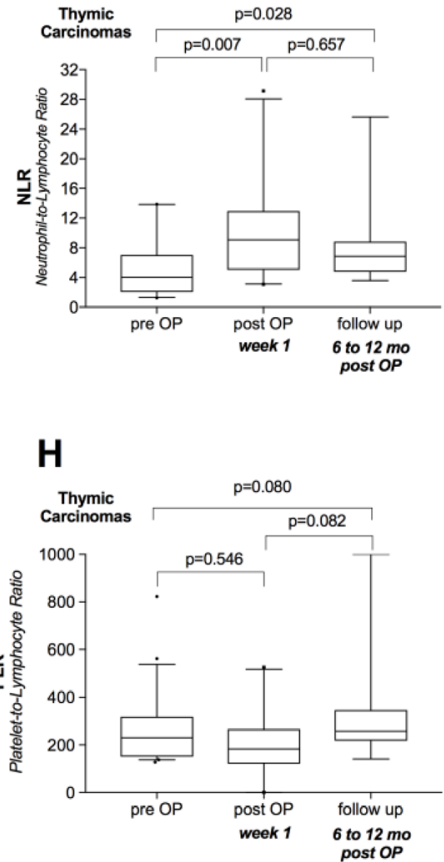

C

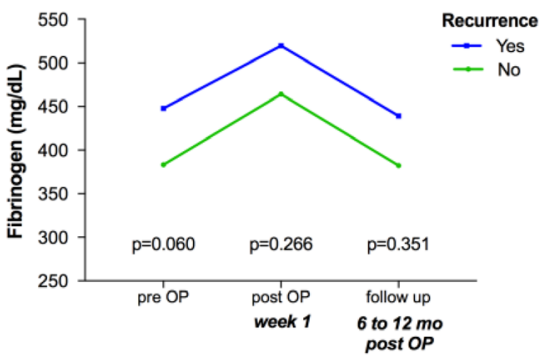

$\mathbf{F}$

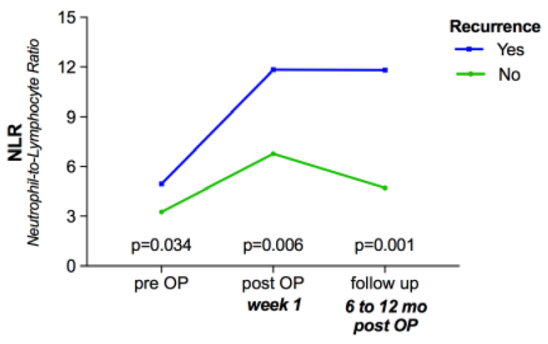

I

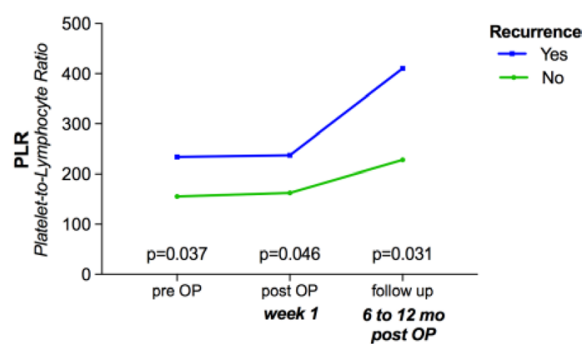

Figure 3: Longitudinal analysis of Fibrinogen, NLR, and PLR. Plots illustrate how surgical tumor resection and recurrence were related to Fibrinogen, NLR, and PLR in thymomas $(\mathbf{A}, \mathbf{D}, \mathbf{G})$ and thymic carcinomas $(\mathbf{B}, \mathbf{E}, \mathbf{H})$, as well as the longitudinal courses of Fibrinogen, NLR, and PLR according to tumor recurrence among TETs (C, F, I). NLR, Neutrophil-to-Lymphocyte Ratio; PLR, Plateletto-Lymphocyte Ratio; mo, months; TETs, thymic epithelial tumors. 
highest in TCs, and lowest in AB thymomas and MNT. TCs are characterized by more aggressive tumor behavior, higher recurrence rates, and worse outcome, while AB thymomas and MNT are associated with a more indolent course and favorable outcome $[8,9,30]$. Similar associations between elevated pretreatment Fibrinogen serum levels and advanced disease stage and worse outcome have been reported in various other malignancies, including nasopharyngeal carcinoma, malignant pleura mesothelioma, ovarian cancer, endometrial cancer, and lymphomas [31-35].

Fibrinogen is an acute phase protein that is produced by the liver in response to proinflammatory cytokines $[36,37]$. It is unclear whether increased Fibrinogen in advanced stage tumors is a bystander effect resulting from an enhanced immune response against higher tumor load, or if Fibrinogen plays an active role in tumor progression via promotion of tumor growth, angiogenesis, and metastasis [38-40]. Here we demonstrated that Fibrinogen staining was absent in malignant thymic epithelial cells, and that Fibrinogen serum concentrations gradually increased with rising invasiveness. These findings indicate that elevated Fibrinogen serum levels are likely a bystander effect of the immune response.

Similar to Fibrinogen, NLR and PLR were found to be highest in patients with TCs and advanced stage tumors that were associated with unfavorable outcome. These results are in line with the literature showing that high pretreatment NLR $(>4.1)$ is associated with larger tumor size, higher Masaoka-Koga tumor stage,

A

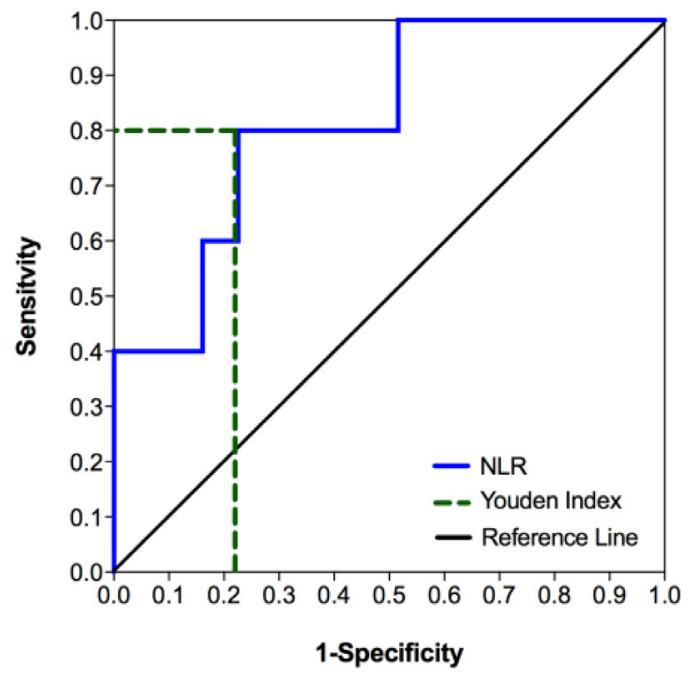

and decreased FFR and OS in patients with TCs [26]. Moreover, associations between high PLR and NLR and worse prognosis are reported in several malignancies, including paranasal sinus carcinomas, laryngeal SCC, esophageal carcinoma, colorectal cancer, and lymphomas $[22,41-46]$. The majority of these studies report that NLR has superior prognostic impact compared to PLR, which is in accordance with our present findings that only NLR was a significant factor associated with worse CSS. However, no previously reported data indicate that NLR, PLR, Fibrinogen, or CRP can be used in a clinically meaningful way to help differentiate among anterior mediastinal tumors (TETs, lymphomas, and germ cell tumors) or to facilitate TET diagnosis.

It is not yet fully understood why increased NLR and PLR correspond with advanced stage tumors. High NLR and PLR imply increased neutrophils and platelets and/or decreased lymphocytes. In established tumors, the balance between inflammation-promoted tumor growth and antitumor immunity is tilted towards pro-tumor inflammation and tumor progression [18]. Pro-tumor inflammation is triggered by tumor and immune cells within the tumor microenvironment, resulting in suppression of lymphocytes or natural killer cells and increased recruitment of neutrophils or platelets [47-49]. Moreover, absolute lymphocyte counts gradually decrease from non-invasive to metastasized TETs, with the lowest lymphocyte numbers in patients with TCs. Although not all lymphocyte subsets are endowed with antitumor activity, lymphocytes are key players in tumor-specific immune responses [50]. Numerous studies demonstrate

\section{B}

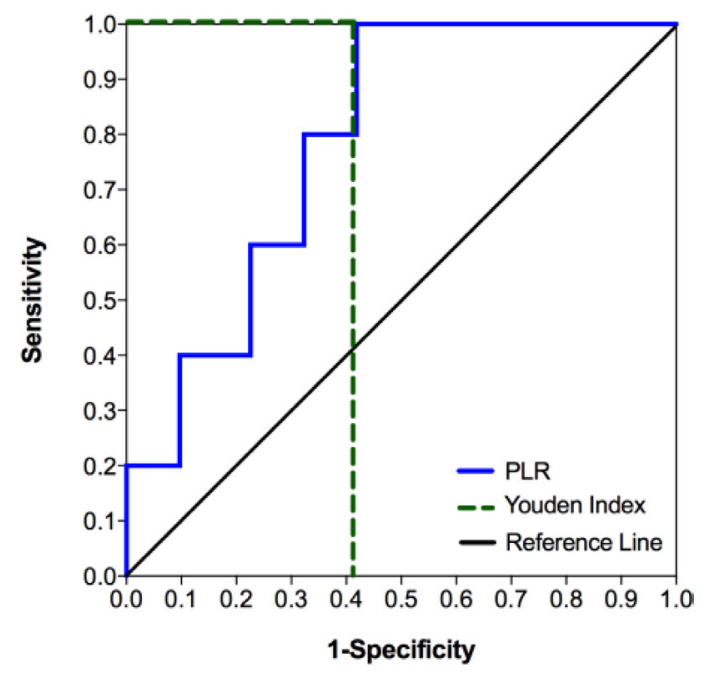

Figure 4: The accuracy of predicting tumor recurrence in patients with TETs based on NLR and PLR values during oncologic follow-up. Receiver operating characteristic (ROC) curves for the use of NLR (A) and PLR (B) to predict tumor recurrence during oncologic follow-up showed area under the curve (AUC) values of $0.819(p=0.024)$ and $0.787(p=0.042)$, respectively. The dotted lines indicate the highest Youden Indices for NLR (Youden Index $=0.574$; sensitivity $=0.800$; specificity $=0.226$; cut-off at 6.6 ) and PLR (Youden Index $=0.581$; sensitivity $=1.000$; specificity $=0.419$; cut-off at 202.5). NLR, Neutrophil-to-Lymphocyte Ratio; PLR, Plateletto-Lymphocyte Ratio. 
a favorable relationship between the amount of tumorinfiltrating lymphocytes (TILs) and outcome in various solid tumors, including oropharyngeal, nasopharyngeal, and esophageal SCC [51-54].

Paraneoplastic MG is characterized by muscle weakness caused by autoantibodies directed against peptides of the neuromuscular junction. Here we found significantly higher absolute lymphocyte counts in tumor patients diagnosed with MG. Similarly, Buckley et al. (2001) and Ströbel et al. (2002) reported significantly higher numbers of naïve $\mathrm{CD}^{+}$and $\mathrm{CD}^{+} \mathrm{T}$ cells in blood samples from patients with TETs and paraneoplastic $\mathrm{MG}$ $[55,56]$. Thymoma patients with and without paraneoplastic MG export mature naïve T cells. "Lymphocyte-rich" B2 thymomas, formerly cortical thymomas, reportedly exhibit higher percentages of mature naïve $\mathrm{CD}^{2} 5^{+} \mathrm{T}$ cells as compared to $\mathrm{AB}$ thymomas (mixed thymomas) or A thymomas (medullary thymomas) [56, 57]. Our present analysis revealed the highest absolute and relative lymphocyte counts in B1 and B2 thymomas, while neutrophil and platelet counts did not significantly differ among the WHO subtypes. Ströbel and coworkers demonstrated that paraneoplastic MG was highly associated with the capability of thymomas to produce and export naïve $\mathrm{CD}^{+} \mathrm{T}$-cells [56]. Intratumorous thymopoiesis being prerequisite for MG development could explain the low incidence, or commonly the absence, of paraneoplastic MG in patients with TCs lacking the required organotypical features $[1,56,58]$.

We also found that patients with TETs who were diagnosed with MG had significantly lower Fibrinogen serum concentrations compared to those without $\mathrm{MG}$, while NLR and PLR did not differ between these two patient groups. Notably, after exclusion of TCs, Fibrinogen
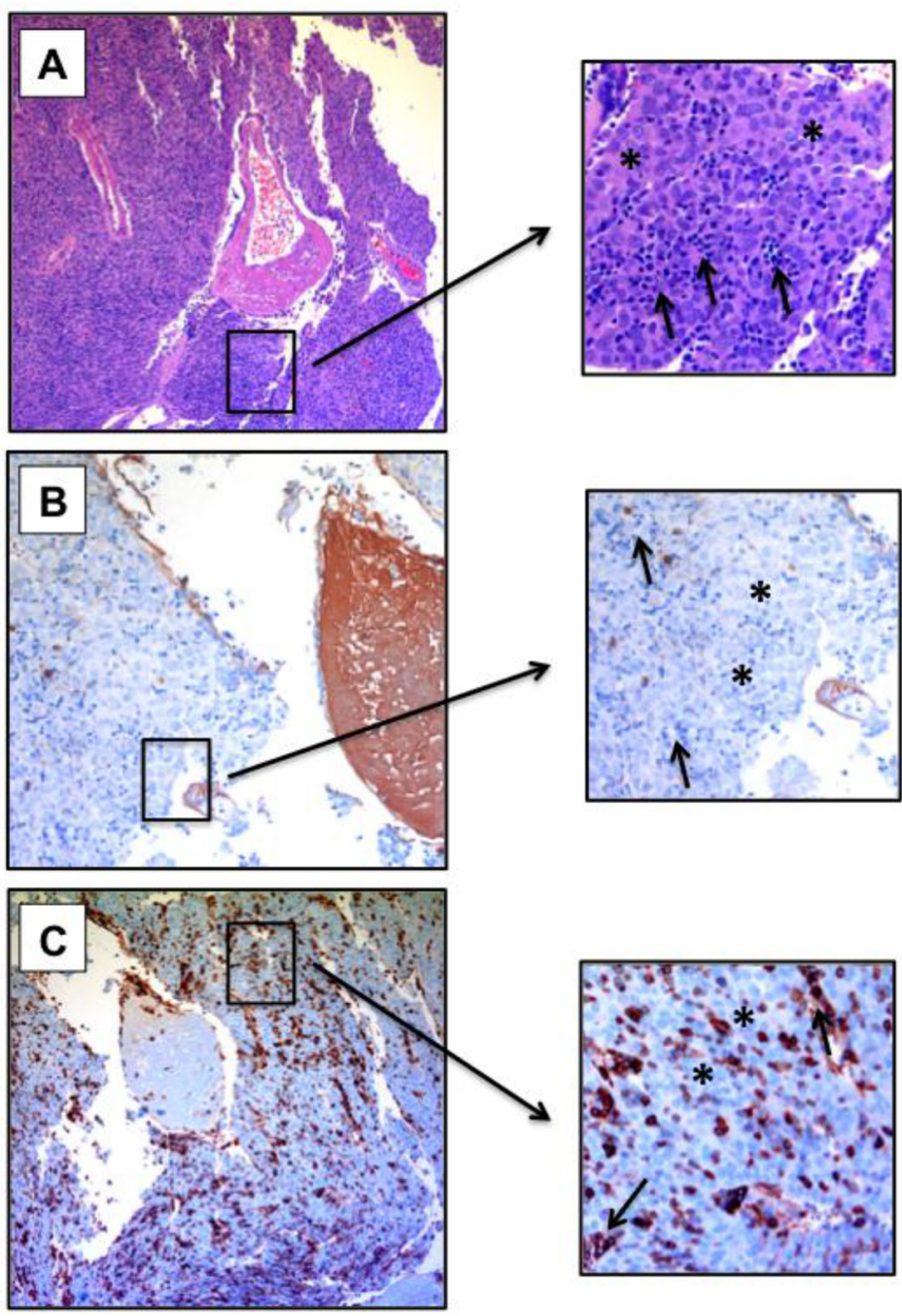

Figure 5: Fibrinogen expression in B2/B3 thymoma. Staining of a B2/B3 thymoma (B3 part) with Hematoxylin-Eosin (A) and for Fibrinogen (B) and CD45 (C) expression. 100× magnification. Asterisks indicate neoplastic thymic epithelial cells. Arrows indicate cells of the hematopoietic lineage. Fibrinogen expression is absent from tumor cells and lymphocytes. Lymphocytes exhibit CD45 expression. 
serum concentrations did not significantly differ in MG-positive compared to MG-negative thymomas $(p=0.051)$. Additionally, Masaoka-Koga tumor stage did not differ in accordance with MG status. These findings led us to postulate that differences in Fibrinogen serum concentrations were more likely caused by presence of TCs than by absence of paraneoplastic MG.

TETs are largely associated with good 10-year OS $[8,9,30]$. Even cases of tumor recurrence (reported in up to $30 \%$ of patients) have excellent 10 -year OS rates of 75.0-90.5\% after radical re-resection [9-11]. Since the specific tumor biology of TETs is characterized by slow tumor growth, relatively high tumor recurrence rates even decades after initial treatment, and excellent survival even after recurrent disease, it is recommended that patients receive life-long oncologic follow-up [11, 59]. At this time, the only recommended tool for oncologic followup is chest CT scanning, which is performed every 3-6 months for the first three years after tumor resection, and then annually thereafter [11]. There are currently no established serum biomarkers that can improve secondary and tertiary prevention. We recently demonstrated significantly increased CRP serum concentrations during the follow-up of patients who developed tumor recurrence. Based on this, we hypothesized that the detection of elevated CRP levels during oncologic surveillance might be helpful to predict tumor recurrence, and suggested CRP serum concentration monitoring might be included in the surveillance of patients with TETs [5].

Longitudinal analyses of Fibrinogen serum concentration, NLR, and PLR revealed that all three markers significantly increased in the immediate postoperative period. This was due to surgical stress that induces an acute phase response and corresponding increase of acute phase proteins [60]. Interestingly, within 6-12 months post-resection, NLR and PLR remained significantly elevated compared to preoperative values, while Fibrinogen serum levels returned to pretreatment concentrations. Stratifying patients based on tumor recurrence revealed that patients who developed tumor recurrence had significantly higher NLR and PLR values during follow-up respectively, 2.5-fold and 1.8-fold higher than in patients without recurrence. We assume that the increased NLR and PLR values in patients with tumor recurrence likely reflects re-induced tumorrelated inflammation, as described above. NLR and PLR, respectively, predicted tumor recurrence with sensitivities of $80 \%$ and $100 \%$, and negative predictive values of $96 \%$ and $100 \%$. Based on these findings, we propose that NLR and PLR are accurate, cheap, easily measurable, and commonly available blood biomarkers that could help in the identification of patients with increased risk of recurrence during oncologic follow-up, potentially enabling early diagnosis and therapy.

We also previously demonstrated significantly increased CRP serum concentrations in cases of tumor recurrence, that high CRP serum levels predict worse FFR, and that CRP is a significant predictive marker for detection of tumor recurrence ( $\left.p=0.037 ; \mathrm{R}^{2}: 0.147\right){ }^{7}$ The predictive power was increased when CRP was used in combination with Fibrinogen $\left(\mathrm{R}^{2}: 0.825\right)$, NLR $\left(\mathrm{R}^{2}\right.$ : $1.000)$, or PLR ( $\left.\mathrm{R}^{2}: 0.726\right)$; however, the significance of each marker for predicting tumor recurrence was lost (Fibrinogen $p=0.352$ and CRP $p=0.112$; NLR $p=0.994$ and CRP $p=0.991$; PLR $p=0.726$ and CRP $p=0.056$ ). While NLR and CRP were significant predictive factors for detection of tumor recurrence, the combination of NLR with CRP or with other systemic biomarkers had no additive effect.

Our study has several weaknesses due to the mostly retrospective design and the single center experience, which limit our ability to draw conclusions. Nonetheless, the strengths of this study are the large number of patients having this rare disease, and the identification of the prognostic and diagnostic power of NLR, PLR, and Fibrinogen among patients with TETs.

Overall, we speculate that the observed increases of Fibrinogen, NLR, and PLR result from cancer-related inflammation, which is in line with our previous findings regarding cancer-related inflammation in TETs $[7,12,13]$. To our knowledge, serum biomarkers are not widely used in patients with TETs. We detected the highest pretreatment levels of Fibrinogen, NLR, and PLR in patients with more aggressive tumor behavior and higher tumor stage. High Fibrinogen, NLR, and PLR were also associated with worse outcome. During oncologic followup, NLR and PLR values were significantly increased in patients with tumor recurrence. We strongly believe that the systemic inflammatory parameters Fibrinogen, NLR, PLR, and CRP have substantial prognostic and diagnostic impact in patients with TETs, warranting future prospective multicenter studies.

\section{MATERIALS AND METHODS}

\section{Study population}

This study was conducted at the Department of Thoracic Surgery, Medical University of Vienna. We analyzed 122 patients with TETs who underwent surgical tumor resection between September 1999 and June 2015. The majority of patients $(80.1 \%)$ had been treated within the past 10 years. All patients underwent preoperative chest CT scans for tumor staging, and some patients further received PET-CT scans or head and abdomen CT scans if advanced tumor stages were suspected. Primary surgical resection alone was performed in $45.9 \%$ of cases, while $54.1 \%$ of patients received multimodal treatment regimens. The median follow-up time was 30.8 months (range, 1 to 173.9 months). Oncologic follow-up involved periodic chest CT scans every 3 to 6 months for the first three years after surgery, followed by annual CT scans in 
accordance with the recommendations of the European Society of Thoracic Surgery (ESTS) [11].

The study also included 51 sex-matched (24 male, 27 female) and age-matched $(54.6 \pm 1.4$ years $)$ healthy volunteers as controls. These control participants underwent one-time measurements of Fibrinogen, NLR, and PLR. These values were used as reference values for analysis with the pretreatment Fibrinogen, NLR, and PLR measurements from patients with TETs.

\section{Outcome analysis}

The main outcome parameters in this study were CSS and FFR. We evaluated outcome and recurrence following the recommendations of the International Thymic Malignancy Interest Group (ITMIG) [59]. Accordingly, CSS was calculated from the date of surgery to the date of death from TET, while unrelated deaths or deaths from unknown causes were censored. FFR was calculated in patients after radical tumor resection ( $\mathrm{R} 0$ ), and was defined as the time from the date of surgery to the date of recurrence.

\section{Fibrinogen, NLR, and PLR measurement}

Fibrinogen, platelets, and white blood cells, including neutrophils and lymphocytes, were measured during the routine preoperative work-up one day before surgery to exclude coagulation disorders/alterations or presence of acute infection. These parameters were also measured between 3 to 7 days postoperatively, and at 6 to 12 months after the initial therapy during oncologic follow-up. All analyses were performed by the department of laboratory medicine. Fibrinogen serum levels were evaluated using the Claus method as previously described [61]. NLR was calculated by dividing the relative neutrophil counts by the relative lymphocyte counts, whereas PLR was calculated by dividing the absolute platelet numbers by the absolute lymphocyte numbers. Preoperative, postoperative, and follow-up Fibrinogen serum levels were available from 112, 98, and 27 patients, respectively. Longitudinal NLR values were available in 101, 95, and 36 patients, respectively, while longitudinal PLR values were available for 96, 95, and 36 patients, respectively. Fibrinogen, NLR, and PLR measurements from 51 healthy sex- and age-matched volunteers served as controls for cross-sectional analysis.

\section{Immunohistochemistry}

Immunohistochemistry was performed using the automated Ventana Benchmark ${ }^{\circledR}$ platform (Ventana Medical Systems, Tuscon, AZ, USA). Staining was performed using monoclonal mouse anti-human CD45 (LCA; 2B11\& PD7/26; Cell Marque, California, USA) and polyclonal rabbit anti-human Fibrinogen/FITC (Dako, Denmark). CD45 staining was performed to identify cells of the hematopoietic lineage. For CD45 staining, heat pre-treatment was performed for $56 \mathrm{~min}$ in Ultra cell conditioner $\mathrm{Nr} 1$ buffer (Ultra CC1; $\mathrm{pH}$ 6). For Fibrinogen staining, Protease 1 was applied for 8 min. Samples were incubated with primary antibodies for $32 \mathrm{~min}$, and then development was performed using the Ultraview Universal Detection DAB-kit following the manufacturer's recommendations.

\section{Statistical methods}

Statistical analyses were performed using SPSS software (version 22; IBM SPSS Inc., IL, USA). All data are reported in the Results section as mean \pm standard error of the mean (SEM). We used the unpaired Student's $t$-test and oneway ANOVA to compare the means of normally distributed variables with two or more than two groups, respectively. The Chi-square test was used to investigate associations between nominal variables. Survival analyses were performed using Kaplan-Meier analysis and the Log-rank test.

Univariable and multivariable Cox regression analyses were performed to evaluate the prognostic impacts of various clinical characteristics, including histology (TC vs. Thymoma), Masaoka-Koga tumor stage (I-II vs. III- IV), Fibrinogen (high vs. low), NLR (high vs. low), and PLR (high vs. low)—on CSS and FFR. We plotted the receiver operating characteristic (ROC) curve calculated the Youden Index to identify an optimal Fibrinogen cut-off value of $452.5 \mathrm{mg} / \mathrm{dL}$ to differentiate between the high and low Fibrinogen subgroups. We used an empiric cut-off value of 4.0 to differentiate between high and low NLR cohorts [32, 62], and a median PLR of 136.5 to determine high and low PLR cohorts. We performed binary logistic regression analysis to evaluate the predictive values of Fibrinogen, NLR, and PLR for detection of tumor recurrence within follow-up. $\mathrm{R}^{2}$ values are indicated as markers for the goodness-of-fit of our models.

\section{Ethics statement}

Ethical approval was obtained from the ethics committee of the Medical University of Vienna. All participating patients and control subjects gave their written informed consent, and all experiments were performed in accordance with the approved ethical guidelines.

\section{Author contributions}

Conceived and designed the experiments: SJ, BG, HJA, and BM. Performed the experiments: SJ, TR, PH, BG, and BM. Analyzed the data: SJ, CB, PH, LM, AS, $\mathrm{HJA}$, and BM. Contributed reagents/materials/analysis tools: BG, EE, LM, AS, WK, HJA, and BM. Wrote the paper: SJ, JM, HJA, and BM. 


\section{ACKNOWLEDGMENTS}

This study was supported and funded by the Christian Doppler Laboratory for Diagnosis and Regeneration of Cardiac and Thoracic Diseases and the surgical research laboratories (ARGE Moser) of the Department of Surgery, Medical University of Vienna. We thank Alexandra Graf from the Department of Medial Statistics, Medical University of Vienna, for her experience and invaluable help in the performance and interpretation of binary logistic regression analyses.

\section{CONFLICTS OF INTEREST}

The authors declare no conflicts of interest.

\section{REFERENCES}

1. Marx A, Chan JK, Coindre JM, Detterbeck F, Girard N, Harris NL, Jaffe ES, Kurrer MO, Marom EM, Moreira AL, Mukai K, Orazi A, Ströbel P. The 2015 World Health Organization Classification of Tumors of the Thymus: Continuity and Changes. J Thorac Oncol. 2015; 10:1383-95.

2. Detterbeck FC, Parsons AM. Management of stage I and II thymoma. Thorac Surg Clin. 2011; 21:59-6.

3. Bhora FY, Chen DJ, Detterbeck FC, Asamura H, Falkson C, Filosso PL, Giaccone G, Huang J, Kim J, Kondo K, Marino M, Marom EM, Nicholson AG, et al. Staging and Prognostic Factors Committee; Advisory Boards. The ITMIG/IASLC Thymic Epithelial Tumors Staging Project: A Proposed Lymph Node Map for Thymic Epithelial Tumors in the Forthcoming 8th Edition of the TNM Classification of Malignant Tumors. J Thorac Oncol. 2014; 9:S88-96.

4. Detterbeck FC, Stratton K, Giroux D, Asamura H, Crowley J, Falkson C, Filosso PL, Frazier AA, Giaccone G, Huang J, Kim J, Kondo K, Lucchi M, et al. Staging and Prognostic Factors Committee; Members of the Advisory Boards; Participating Institutions of the Thymic Domain. The IASLC/ITMIG Thymic Epithelial Tumors Staging Project: proposal for an evidence-based stage classification system for the forthcoming (8th) edition of the TNM classification of malignant tumors. J Thorac Oncol. 2014; 9:S65-72.

5. Kondo K, Van Schil P, Detterbeck FC, Okumura M, Stratton K, Giroux D, Asamura H, Crowley J, Falkson C, Filosso PL, Giaccone G, Huang J, Kim J, et al. Staging and Prognostic Factors Committee; Members of the Advisory Boards; Participating Institutions of the Thymic Domain. The IASLC/ITMIG Thymic Epithelial Tumors Staging Project: proposals for the $\mathrm{N}$ and $\mathrm{M}$ components for the forthcoming (8th) edition of the TNM classification of malignant tumors. J Thorac Oncol. 2014; 9:S81-7.

6. Nicholson AG, Detterbeck FC, Marino M, Kim J, Stratton K, Giroux D, Asamura H, Crowley J, Falkson C, Filosso PL, Giaccone G, Huang J, Kondo K, et al. Staging and
Prognostic Factors Committee; Members of the Advisory Boards; Participating Institutions of the Thymic Domain. The IASLC/ITMIG Thymic Epithelial Tumors Staging Project: proposals for the T Component for the forthcoming (8th) edition of the TNM classification of malignant tumors. J Thorac Oncol. 2014; 9:73-80.

7. Janik S, Bekos C, Hacker P, Raunegger T, Ghanim B, Einwallner E, Beer L, Klepetko W, Müllauer L, Ankersmit HJ, Moser B. Elevated CRP levels predict poor outcome and tumor recurrence in patients with thymic epithelial tumors: A pro- and retrospective analysis. Oncotarget. 2017; 8:47090-47102. https://doi.org/10.18632/oncotarget.17478.

8. Moser B, Scharitzer M, Hacker S, Ankersmit J, Matilla JR, Lang G, Aigner C, Taghavi S, Klepetko W. Thymomas and thymic carcinomas: prognostic factors and multimodal management. Thorac Cardiovasc Surg. 2014; 62:153-60.

9. Kondo K, Yoshizawa K, Tsuyuguchi M, Kimura S, Sumitomo M, Morita J, Miyoshi T, Sakiyama S, Mukai K, Monden Y. WHO histologic classification is a prognostic indicator in thymoma. Ann Thorac Surg. 2004; 77:1183-8.

10. Marulli G, Margaritora S, Lucchi M, Cardillo G, Granone P, Mussi A, Carleo F, Perissinotto E, Rea F. Surgical treatment of recurrent thymoma: is it worthwhile? $\uparrow$. Eur J Cardiothorac Surg. 2016; 49:327-32.

11. Ruffini E, Detterbeck F, Van Raemdonck D, Rocco G, Thomas P, Weder W, Brunelli A, Evangelista A, Venuta F; European Association of Thoracic Surgeons (ESTS) Thymic Working Group. Tumours of the thymus: a cohort study of prognostic factors from the European Society of Thoracic Surgeons database. Eur J Cardiothorac Surg. 2014; 46:361-8.

12. Janik S, Schiefer AI, Bekos C, Hacker P, Haider T, Moser J, Klepetko W, Müllauer L, Ankersmit HJ, Moser B. HSP27 and 70 expression in thymic epithelial tumors and benign thymic alterations: diagnostic, prognostic and physiologic implications. Sci Rep. 2016; 6:24267.

13. Moser B, Janik S, Schiefer AI, Müllauer L, Bekos C, Scharrer A, Mildner M, Rényi-Vámos F, Klepetko W, Ankersmit HJ. Expression of RAGE and HMGB1 in thymic epithelial tumors, thymic hyperplasia and regular thymic morphology. PLoS One. 2014; 9:e94118.

14. Ströbel P. Old wine in new bottles: C-reactive protein (CRP) is a promising tumor marker in thymic epithelial tumors. Mediastinum. 2017.

15. Nguyen A, Bhavsar S, Riley E, Caponetti G, Agrawal D. Clinical Value of High Mobility Group Box 1 and the Receptor for Advanced Glycation End-products in Head and Neck Cancer: A Systematic Review. Int Arch Otorhinolaryngol. 2016; 20:382-389.

16. Takeuchi H, Kawanaka H, Fukuyama S, Kubo N, Hiroshige S, Yano T. Comparison of the prognostic values of preoperative inflammation-based parameters in patients with breast cancer. PLoS One. 2017; 12:e0177137. 
17. Khalil AA, Kabapy NF, Deraz SF, Smith C. Heat shock proteins in oncology: diagnostic biomarkers or therapeutic targets? Biochim Biophys Acta. 2011; 1816:89-104.

18. Grivennikov SI, Greten FR, Karin M. Immunity, inflammation, and cancer. Cell. 2010; 140:883-99.

19. Hanahan D, Weinberg RA. Hallmarks of cancer: the next generation. Cell. 2011; 144:646-74.

20. Qian BZ, Pollard JW. Macrophage diversity enhances tumor progression and metastasis. Cell. 2010; 141:39-51.

21. de Visser KE, Coussens LM. The inflammatory tumor microenvironment and its impact on cancer development. Contrib Microbiol. 2006; 13:118-37.

22. Pedrazzani C, Mantovani G, Fernandes E, Bagante F, Luca Salvagno G, Surci N, Campagnaro T, Ruzzenente A, Danese E, Lippi G, Guglielmi A. Assessment of neutrophil-tolymphocyte ratio, platelet-to-lymphocyte ratio and platelet count as predictors of long-term outcome after R0 resection for colorectal cancer. Sci Rep. 2017; 7:1494.

23. Bowen RC, Little NAB, Harmer JR, Ma J, Mirabelli LG, Roller KD, Breivik AM, Signor E, Miller AB, Khong HT. Neutrophil-to-lymphocyte ratio as prognostic indicator in gastrointestinal cancers: a systematic review and metaanalysis. Oncotarget. 2017; 8:32171-32189. https://doi. org/10.18632/oncotarget.16291.

24. Su L, Zhang M, Zhang W, Cai C, Hong J. Pretreatment hematologic markers as prognostic factors in patients with nasopharyngeal carcinoma: A systematic review and metaanalysis. Medicine (Baltimore). 2017; 96:e6364.

25. Perisanidis C, Psyrri A, Cohen EE, Engelmann J, Heinze G, Perisanidis B, Stift A, Filipits M, Kornek G, Nkenke E. Prognostic role of pretreatment plasma fibrinogen in patients with solid tumors: A systematic review and metaanalysis. Cancer Treat Rev. 2015; 41:960-70.

26. Yuan ZY, Gao SG, Mu JW, Xue Q, Mao YS, Wang DL, Zhao J, Gao YS, Huang JF, He J. Prognostic value of preoperative neutrophil-lymphocyte ratio is superior to platelet-lymphocyte ratio for survival in patients who underwent complete resection of thymic carcinoma. J Thorac Dis. 2016; 8:1487-96.

27. Tseng YC, Tseng YH, Kao HL, Hsieh CC, Chou TY, Goan YG, Hsu WH, Hsu HS. Long term oncological outcome of thymoma and thymic carcinoma - an analysis of 235 cases from a single institution. PLoS One. 2017; 12:e0179527.

28. Huang J, Rizk NP, Travis WD, Riely GJ, Park BJ, Bains MS, Dycoco J, Flores RM, Downey RJ, Rusch VW. Comparison of patterns of relapse in thymic carcinoma and thymoma. J Thorac Cardiovasc Surg. 2009; 138:26-31.

29. Zhao Y, Shi J, Fan L, Hu D, Yang J, Zhao H. Surgical treatment of thymoma: an 11-year experience with 761 patients. Eur J Cardiothorac Surg. 2016; 49:1144-9.

30. Ströbel P, Bauer A, Puppe B, Kraushaar T, Krein A, Toyka K, Gold R, Semik M, Kiefer R, Nix W, Schalke B, MüllerHermelink HK, Marx A. Tumor recurrence and survival in patients treated for thymomas and thymic squamous cell carcinomas: a retrospective analysis. J Clin Oncol. 2004; 22:1501-9.

31. He SS, Wang Y, Yang L, Chen HY, Liang SB, Lu LX, Chen Y. Plasma Fibrinogen Correlates with Metastasis and is Associated with Prognosis in Human Nasopharyngeal Carcinoma. J Cancer. 2017; 8:403-409.

32. Ghanim B, Hoda MA, Klikovits T, Winter MP, Alimohammadi A, Grusch M, Dome B, Arns M, Schenk P, Jakopovic M, Samarzija M, Brcic L, Filipits M, et al. Circulating fibrinogen is a prognostic and predictive biomarker in malignant pleural mesothelioma. Br J Cancer. 2014; 110:984-90.

33. Polterauer S, Grimm C, Seebacher V, Concin N, Marth C, Tomovski C, Husslein H, Leipold H, Hefler-Frischmuth $\mathrm{K}$, Tempfer C, Reinthaller A, Hefler L. Plasma fibrinogen levels and prognosis in patients with ovarian cancer: a multicenter study. Oncologist. 2009; 14:979-85.

34. Seebacher V, Polterauer S, Grimm C, Husslein H, Leipold H, Hefler-Frischmuth K, Tempfer C, Reinthaller A, Hefler L. The prognostic value of plasma fibrinogen levels in patients with endometrial cancer: a multi-centre trial. Br J Cancer. 2010; 102:952-6.

35. Troppan KT, Melchardt T, Wenzl K, Schlick K, Deutsch A, Bullock MD, Reitz D, Beham-Schmid C, Weiss L, Neureiter D, Tränkenschuh W, Greil R, Neumeister P, et al. The clinical significance of fibrinogen plasma levels in patients with diffuse large B cell lymphoma. J Clin Pathol. 2016; 69:326-30.

36. Tennent GA, Brennan SO, Stangou AJ, O'Grady J, Hawkins $\mathrm{PN}$, Pepys MB. Human plasma fibrinogen is synthesized in the liver. Blood. 2007; 109:1971-4.

37. Yamaguchi T, Yamamoto Y, Yokota S, Nakagawa M, Ito M, Ogura T. Involvement of interleukin-6 in the elevation of plasma fibrinogen levels in lung cancer patients. Jpn J Clin Oncol. 1998; 28:740-4.

38. Sahni A, Simpson-Haidaris PJ, Sahni SK, Vaday GG, Francis CW. Fibrinogen synthesized by cancer cells augments the proliferative effect of fibroblast growth factor-2 (FGF-2). J Thromb Haemost. 2008; 6:176-83.

39. Palumbo JS, Potter JM, Kaplan LS, Talmage K, Jackson DG, Degen JL. Spontaneous hematogenous and lymphatic metastasis, but not primary tumor growth or angiogenesis, is diminished in fibrinogen-deficient mice. Cancer Res. 2002; 62:6966-72.

40. Laurens N, Koolwijk P, de Maat MP. Fibrin structure and wound healing. J Thromb Haemost. 2006; 4:932-9.

41. Turri-Zanoni M, Salzano G, Lambertoni A, Giovannardi M, Karligkiotis A, Battaglia P, Castelnuovo P. Prognostic value of pretreatment peripheral blood markers in paranasal sinus cancer: Neutrophil-to-lymphocyte and platelet-tolymphocyte ratio. Head Neck. 2017; 39:730-736.

42. Hsueh C, Tao L, Zhang M, Cao W, Gong H, Zhou J, Zhou L. The prognostic value of preoperative neutrophils, platelets, lymphocytes, monocytes and calculated ratios in patients 
with laryngeal squamous cell cancer. Oncotarget. 2017; 8:60514-60527. https://doi.org/10.18632/oncotarget.16234.

43. Yodying H, Matsuda A, Miyashita M, Matsumoto S, Sakurazawa N, Yamada M, Uchida E. Prognostic Significance of Neutrophil-to-Lymphocyte Ratio and Platelet-to-Lymphocyte Ratio in Oncologic Outcomes of Esophageal Cancer: A Systematic Review and Metaanalysis. Ann Surg Oncol. 2016; 23:646-54.

44. Wang J, Zhou M, Xu JY, Yang YG, Zhang QG, Zhou RF, Chen B, Ouyang J. Prognostic role of pretreatment neutrophil-lymphocyte ratio in patients with diffuse large B-cell lymphoma treated with RCHOP. Medicine (Baltimore). 2016; 95:e4893.

45. Marcheselli R, Bari A, Tadmor T, Marcheselli L, Cox MC, Pozzi S, Ferrari A, Baldini L, Gobbi P, Aviv A, Pugliese G, Federico M, Polliack A, et al. Neutrophil-lymphocyte ratio at diagnosis is an independent prognostic factor in patients with nodular sclerosis Hodgkin lymphoma: results of a large multicenter study involving 990 patients. Hematol Oncol. 2017; 35:561-56.

46. Seo J, Kim WS, Kim JS, Kim SJ, Lee JH, Hong JS, Lee GW, Oh SY, Lee JH, Yoon DH, Lee WS, Kim HJ, Kwak JY, et al. Platelet to lymphocyte ratio (PLR) retains independent prognostic significance in advanced stage marginal zone lymphoma patients treated with rituximab, cyclophosphamide, vincristine, and prednisone combination chemotherapy (R-CVP): Consortium for Improving Survival of Lymphoma trial. Blood Res. 2017; 52:200-206.

47. Petrie HT, Klassen LW, Kay HD. Inhibition of human cytotoxic $\mathrm{T}$ lymphocyte activity in vitro by autologous peripheral blood granulocytes. J Immunol. 1985; 134:230-4.

48. Templeton AJ, McNamara MG, Šeruga B, Vera-Badillo FE, Aneja P, Ocaña A, Leibowitz-Amit R, Sonpavde G, Knox JJ, Tran B, Tannock IF, Amir E. Prognostic role of neutrophil-to-lymphocyte ratio in solid tumors: a systematic review and meta-analysis. J Natl Cancer Inst. 2014; 106:dju124.

49. Sionov RV, Fridlender ZG, Granot Z. The Multifaceted Roles Neutrophils Play in the Tumor Microenvironment. Cancer Microenviron. 2015; 8:125-58.

50. Senovilla L, Vacchelli E, Galon J, Adjemian S, Eggermont A, Fridman WH, Sautès-Fridman C, Ma Y, Tartour E, Zitvogel L, Kroemer G, Galluzzi L. Trial watch: Prognostic and predictive value of the immune infiltrate in cancer. Oncoimmunology. 2012; 1:1323-1343.

51. De Meulenaere A, Vermassen T, Aspeslagh S, Deron P, Duprez F, Laukens D, Van Dorpe J, Ferdinande L, Rottey S. Tumor PD-L1 status and CD8+ tumor-infiltrating T cells: markers of improved prognosis in oropharyngeal cancer. Oncotarget. 2017; 8:80443-80452. https://doi. org/10.18632/oncotarget.19045.

52. Ooft ML, van Ipenburg JA, Braunius WW, Zuur CI, Koljenović S, Willems SM. Prognostic role of tumor infiltrating lymphocytes in EBV positive and EBV negative nasopharyngeal carcinoma. Oral Oncol. 2017; 71:16-25.

53. Jesinghaus M, Steiger K, Slotta-Huspenina J, Drecoll E, Pfarr N, Meyer P, Konukiewitz B, Bettstetter M, Wieczorek K, Ott K, Feith M, Langer R, Weichert W, et al. Increased intraepithelial CD3+ T-lymphocytes and high PD-L1 expression on tumor cells are associated with a favorable prognosis in esophageal squamous cell carcinoma and allow prognostic immunogenic subgrouping. Oncotarget. 2017; 8:46756-46768. https://doi.org/10.18632/oncotarget.18606.

54. Vesely MD, Kershaw MH, Schreiber RD, Smyth MJ. Natural innate and adaptive immunity to cancer. Annu Rev Immunol. 2011; 29:235-71.

55. Buckley C, Douek D, Newsom-Davis J, Vincent A, Willcox N. Mature, long-lived CD4+ and CD8+ T cells are generated by the thymoma in myasthenia gravis. Ann Neurol. 2001; 50:64-72.

56. Ströbel P, Helmreich M, Menioudakis G, Lewin SR, Rüdiger T, Bauer A, Hoffacker V, Gold R, Nix W, Schalke B, Elert O, Semik M, Müller-Hermelink HK, et al. Paraneoplastic myasthenia gravis correlates with generation of mature naive CD4(+) T cells in thymomas. Blood. 2002; 100:159-66.

57. Hoffacker V, Schultz A, Tiesinga JJ, Gold R, Schalke B, Nix W, Kiefer R, Müller-Hermelink HK, Marx A. Thymomas alter the T-cell subset composition in the blood: a potential mechanism for thymoma-associated autoimmune disease. Blood. 2000; 96:3872-9.

58. Okumura M, Miyoshi S, Fujii Y, Takeuchi Y, Shiono H, Inoue M, Fukuhara K, Kadota Y, Tateyama H, Eimoto T, Matsuda H. Clinical and functional significance of WHO classification on human thymic epithelial neoplasms: a study of 146 consecutive tumors. Am J Surg Pathol. 2001; 25:103-10.

59. Huang J, Detterbeck FC, Wang Z, Loehrer PJ Sr. Standard outcome measures for thymic malignancies. J Thorac Oncol. 2010; 5:2017-23.

60. Asteriou C, Lazopoulos A, Rallis T, Gogakos AS, Paliouras D, Tsakiridis K, Zissimopoulos A, Tsavlis D, Porpodis K, Hohenforst-Schmidt W, Kioumis I, Organtzis J, Zarogoulidis K, et al. Video-assisted thoracic surgery reduces early postoperative stress. A single-institutional prospective randomized study. Ther Clin Risk Manag. 2016; 12:59-65.

61. Clauss A. Rapid physiological coagulation method in determination of fibrinogen. Acta Haematol. 1957; 17:237-46.

62. Malietzis G, Giacometti M, Kennedy RH, Athanasiou T, Aziz O, Jenkins JT. The emerging role of neutrophil to lymphocyte ratio in determining colorectal cancer treatment outcomes: a systematic review and meta-analysis. Ann Surg Oncol. 2014; 21:3938-46. 